\title{
Schistosoma haematobium infections acquired in Corsica, France, August 2013
}

M C Holtfreter ${ }^{1}$, H Moné2,3, I Müller-Stöver ${ }^{1}$, G Mouahid²,3, J Richter (Joachim.Richter@med.uni-duesseldorf.de)

1. Tropical Medicine Unit, Department of Gastroenterology, Hepatology and Infectious Diseases, Heinrich-Heine-University Düsseldorf, Düsseldorf, Germany

2. Ecologie et Evolution des Interactions, UMR 5244, Université de Perpignan, Perpignan, France

3. Centre national de la recherche scientifique (CNRS), Ecologie et Evolution des Interactions, Perpignan, France

Citation style for this article:

Holtfreter MC, Moné H, Müller-Stöver I, Mouahid G, Richter J. Schistosoma haematobium infections acquired in Corsica, France, August 2013. Euro Surveill. 2014;19(22): pii=20821. Available online: $\mathrm{http}: / /$ www.eurosurveillance.org/ViewArticle.aspx?Articleld=20821

Article submitted on 27 May 2014 / published on 05 June 2014

A 12 year-old boy in Germany developed urinary schistosomiasis in January 2014. He had bathed in rivers in south-eastern Corsica five months earlier. Before this case, human schistomiasis had not been reported on the island, although its vector, the snail Bulinus truncatus, locally transmitted the zoonotic Schistosoma bovis. The boy's father excreted S. haematobium ova that were not viable; the boy's three siblings had a positive serology against schistosomes.

\section{Schistosomiasis cases reported in Germany in 2014}

In January 2014, a 12 year-old German boy noticed painless excretion of bloody urine. He was referred by his paediatrician to a nearby urological hospital where ultrasonography showed focal thickening of the bladder wall. Since no bacterial infectious agent was detected, cystoscopy was performed, as a result of which severe cystitis was detected. Histological examination of a biopsy taken from the bladder wall showed granulomatous inflammation and schistosomiasis was suspected. As the boy had had no exposure in known schistosomiasis-endemic regions, his family took him to the Tropical Diseases Service in Düsseldorf, Germany.

Microscopy of a 24-hour urine sample collected from on the first day he presented until the following day and filtered through a nuclepore microfilter revealed viable ova of Schistosoma haematobium (Figure).

The boy was treated with a single standard dose of praziquantel $(40 \mathrm{mg} / \mathrm{kg}$ body weight) and re-treated three weeks later with the same dose, to be sure to achieve complete cure of the infection. During 24 days after therapy, he had various attacks of haematuria, sometimes with temporary large blood clots inside the bladder. Upper urinary tract infection was not observed. Bacterial coinfections including tuberculosis

\section{FIGURE}

Ova of Schistosoma haematobium seen by microscopy of a microfiltrate of urine from a boy with urinary schistosomiasis, Germany, March 2014

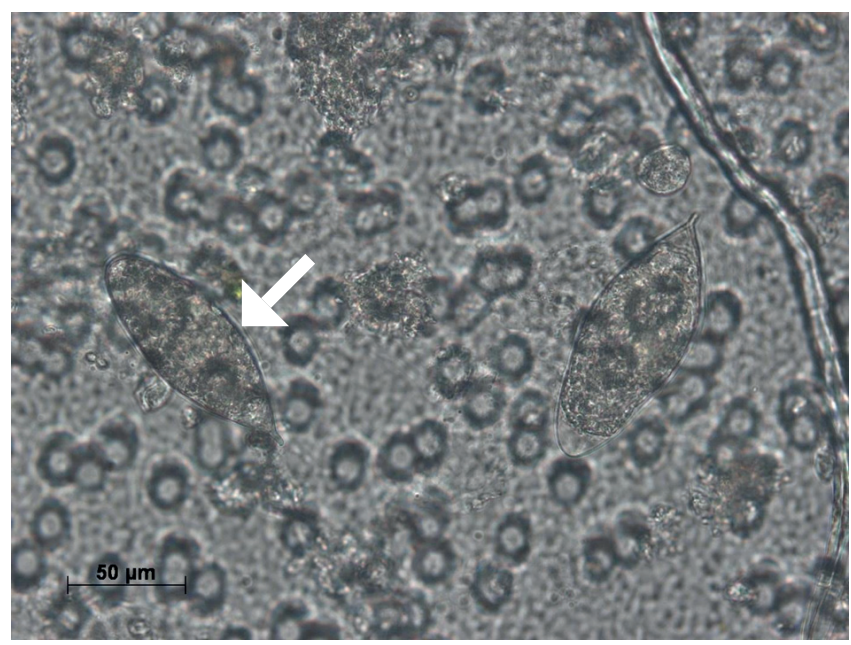

Ova are indicated by arrows.

were ruled out by urine cultures, PCR and interferongamma release assay.

Investigations of the boy's five family members revealed non-viable $S$. haematobium ova in the urine of his father. Repeated examinations of enriched stool samples were negative for all family members. On the other hand, schistosomiasis serology against cercarial and adult antigens (by enzyme-linked immunosorbent assay (ELISA), immunofluorescence test (IFT)) was highly positive in all four children (including the boy) and the father, but not the mother.

Detailed history again confirmed that the boy and his family had never travelled outside Europe. His most 
southerly travel was to Spain, where he had not bathed in surface fresh water, and southern France including south-eastern Corsica, where the boy had spent his holidays together with his family in August 2013 and bathed frequently in various rivers. The only place where the mother did not bathe together with her family was Cavu River.

\section{Background}

Schistosomiasis is endemic in in 78 countries of the tropical and subtropical world [1]. The World Health Organization in 2012 estimated that 249 million people required preventive antiparasitic therapy for schistosomiasis [1]. One of the six Schistosoma species, i.e. S. haematobium, causes urinary schistosomiasis and is endemic in Africa and the Arabian Peninsula [2].

The life cycle of this helminth involves man and freshwater snails [2]. Humans constitute the definitive host, the freshwater snail of the genus Bulinus spp. the intermediate host. The habitat of the snail is shallow waters of rivers or lakes, where the snail usually lives attached to water plants. The snail releases mobile worm larvae called cercariae, which actively reach the definitive host and penetrate their skin. The larvae reach the bloodstream and end up in the portal system, where the worm larvae grow and mature to female and male adult worms. The adult worms mate and descend to the plexus vesicalis, where the female worms start to lay their ova into the urinary bladder mucosa. The ova are excreted into the urine of the definitive host. When the ova reach fresh water, the intraovular larvae called miracidia hatch and swim towards the snails, where the cycle is completed. The bladder mucosa is damaged by the inflammatory response to the intraovular antigens resulting in ulcerations, papillomata and polyps of the bladder wall. Complications include bladder carcinoma, upper urinary tract infection and involvement of the reproductive tract [2].

\section{Discussion}

To the best of our knowledge, this is the first report in the scientific literature of autochthonous human schistosomiasis acquired in Europe since its elimination in the 1960 [2]. Similar cases among French tourists visiting the same sites in Corsica have been reported recently $[3,4]$.

As the family had never travelled to known schistosomiasis-endemic areas, the most likely location for acquiring schistosomiasis was south-eastern Corsica, as supported also by the French tourists who were presumably infected in the same area $[3,4]$. Schistosomiasis has not been described as endemic in Corsica so far; however, Bulinus truncatus, the vector (snail) of $S$. haematobium is known to be endemic in some areas of south Europe, including Corsica, where it transmitted zoonotic S. bovis, which in humans may cause skin irritation (cercarial dermatitis) due to the unsuccessful skin penetration of zoonotic cercariae [5-7]. Generally, Bulinus spp. snails are very tolerant to temperature change as they can survive temperatures between $2{ }^{\circ} \mathrm{C}$ and $40{ }^{\circ} \mathrm{C}[8,9]$. Malacological investigations have shown that $S$. haematobium can develop in Bulinus spp. at temperatures around $20^{\circ} \mathrm{C}$ [9]; however, the optimum temperature for infection of Bulinus spp. with $\mathrm{S}$. haematobium miracidia is between $20^{\circ} \mathrm{C}$ and $30{ }^{\circ} \mathrm{C}[9,10]$. Cercarial shedding is also temperature dependent, with more cercariae shed at higher temperatures than at lower temperatures [11]; however, cercarial shedding can occur between $10^{\circ} \mathrm{C}$ and $30^{\circ} \mathrm{C}$ [12].

Physicians, especially urologists, should be alerted to the potential risk of schistosomiasis in individuals with haematuria or unclear genital symptoms who have never visited known schistosomiasis-endemic areas. Besides Corsica, schistosomiasis might be reintroduced to other endemic or formerly endemic areas for Bulinus snails, including southern Portugal, Sardinia, Sicily, Cyprus and Greece [11,13-16]. Since schistosomiasis is a chronic disease that may start with mild non-specific pruriginous cutaneous, urinary or genital tract symptoms $[2,17,18]$, people who experience such symptoms and were exposed to surface fresh water in southern Corsica during past summers should be investigated [4].

Further studies are needed to identify the location of transmission sites, the focus and seasonality of transmission of $S$. haematobium in southern Corsica and to determine the origins of its introduction. Results of molecular genetic studies to identify the origin of the parasite and malacological studies to study the biology of the vector snails as well as the parasite's presence in the vector snails are pending.

\section{Acknowledgments}

There was no specific financial support. The case described occurred in a clinical routine context. We would like to thank the family involved for the enthusiastic support. Conflict of interest

None declared.

\section{Authors' contributions}

JR and IMS took clinical care of the patients. MH, HM and GM performed the parasitological investigations. JR, MH, HM and GM looked for infected snails in Cavu River. All authors participated in writing the manuscript.

References

1. World Health Organization (WHO). Geneva: WHO. [Accessed 26 May 2014]. Schistosomiasis. Fact sheet $\mathrm{N}^{\circ} 115$. Available from: http://www.who.int/mediacentre/factsheets/fs115/en/

2. Davis A. Schistosomiasis. In: Cook GC, Zumla Al, editors. Manson's tropical diseases. 22nd ed. Edinburgh: Saunders, Elsevier; 2009. p. 1425-60.

3. ProMED-mail. Schistosomiasis - France: (Corsica). Archive Number 20140518.2480187. 18 May 2014. Available from: http://www.promedmail.org

4. European Centre for Disease Prevention and Control (ECDC). Rapid risk assessment: local transmission of Schistosoma haematobium in Corsica, France - 16 May 2014. Stockholm 
ECDC; 2014. Available from: http://www.ecdc.europa.eu/en/ publications/Publications/schistosoma-haematobium-riskassessment-France-Germany.pdf

5. Dolfus R. [On the presence in France and Corsica of Bulinus contortus (Michaud), intermediate host of Schistosoma haematobium (Bilharz). Preliminary note]. Bull Soc Pathol Exot. 1922;15(4):208-212. French.

6. Gretillat S. [Epidemiology of certain trematode diseases of domestic animals in Corsica (bovine bilharziosis and bovine and ovine distomiasis). Observations conducted during a mission accomplished during the autumn of 1962]. Ann Parasitol Hum Comp. 1963;38:471-81. French.

7. Doby JM, Rault B, Deblock S, Chabaud A. [Snails and bilharziasis in Corsica. Distribution, frequency and biology of "Bulinus truncatus"]. Ann Parasitol Hum Comp. 1966;41(4):33749. French.

8. Watson JM. Ecology and distribution of Bulinus truncatus in the Middle East; with comments on the effect of some human activities in their relationship to the snail host on the incidence of bilharziasis haematobia in the Middle East and Africa. Bull World Health Organ. 1958;18(5-6):833-94

9. Chu KY, Massoud J, Sabbaghian H. Host-parasite relationship of Bulinus truncatus and Schistosoma haematobium in Iran. 3. Effect of water temperature on the ability of miracidia to infect snails. Bull World Health Organ. 1966;34(1):131-3.

10. Blankespoor HD, Babiker SM, Blankespoor CL. Influence of temperature on the development of Schistosoma haematobium in Bulinus truncatus. Journal of Medical and Applied Malacology. 1989;1:123-31.

11. Rollinson D, Stothard JR, Southgate VR. Interactions between intermediate snail hosts of the genus Bulinus and schistosomes of the Schistosoma haematobium group. Parasitology. 2001;123 Suppl: S245-60. http://dx.doi. org/10.1017/So031182001008046

12. McClelland WJ.The production of cercariae by Schistosoma mansoni and S. haematobium and methods for estimating the numbers of cercariae in suspension. Bull World Health Organ. 1965;33(2):270-6.

13. Biocca E. [Mollusc vectors of schistosomiasis in Sardinia and in the Mediterranean area: taxonomy and epidemiology]. Parassitologia. 1980;22(3):247-55. Italian.

14. Gracio MA. Distribution and habitats of six species of freshwater pulmonate snails in Algarve, southern Portugal. Malacol Rev. 1983;16:17-23.

15. Schütt $H$. [Bulinus truncatus in Crete]. Zeitschrift für Angewandte Zoologie. 1987;74(2):243-5. German.

16. Ferreira PM, Calado MM, Ferreira CC, Guimarães M, Gracio MA. [Study of freshwater molluscs of Portugal between 2000 and 2006]. Acta Parasitologica Portuguesa 2006;13(1-2):23-5. Portuguese.

17. Meltzer E, Artom G, Marva E, Assous MV, Rahav G, Schwartz E. Schistosomiasis among travelers: new aspects of an old disease. Emerg Infect Dis. 2006;12(11):1696-700. http://dx.doi. org/10.3201/eid1211.060340

18. Catteau X, Fakhri A, Albert V, Doukouré B, Noël JC. Genital schistosomiasis in European women. ISRN Obstet Gynecol. 2011;2011:242140. http://dx.doi.org/10.5402/2011/242140 